\title{
Synthesis and characterisation of gibbsite nanostructures
}

\author{
Ye Liu, ${ }^{\mathrm{a}}$ Ding Ma, ${ }^{\mathrm{a} *}$ Ross A. Blackley, ${ }^{\mathrm{b}}$ Wuzong Zhou, ${ }^{\mathrm{b}}$ Xiuwen Han, ${ }^{\mathrm{a}}$ Xinhe Bao ${ }^{\mathrm{a}}$
}

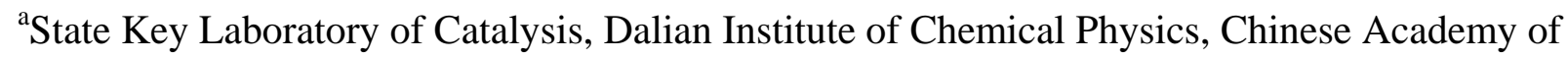
Sciences, Dalian 116023, P. R. China.

${ }^{\mathrm{b}}$ School of Chemistry, University of St. Andrews, St. Andrews, KY16 9ST, United Kingdom.

\section{Supporting Information}


I. The result of Pawley profile fitting of the XRD pattern of as-synthesized gibbsite nanorods.

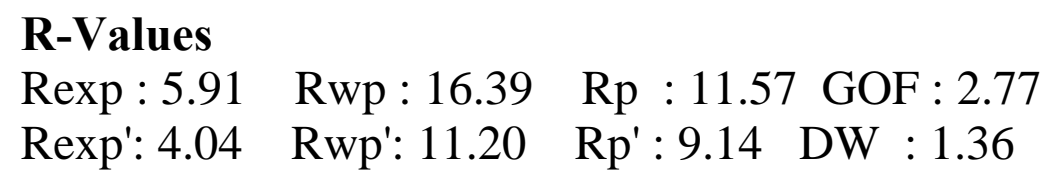

Corrections

Zero Error

$0.0502(14)$

hkl Phase - 1 Pawley method

Phase name

R-Bragg

gibbsite

Space group

2.852

Cell Volume $(\AA \wedge 3)$

$\mathrm{P} 121 / \mathrm{n} 1$

PV_TCHZ peak type

V

W

Z

$-0.137(19)$

$0.0141(22)$

$\mathrm{X}$

0

Y

$0.221(20)$

0

Lattice parameters
a $(\AA)$
b $(\AA)$
8.67881(51)
c $(\AA)$
5.07436(27)
beta $\left(^{\circ}\right)$
9.73081(64)
94.5490(51)

Experimental, calculated, and difference XRD profile are shown in Figure 1.

II. The result of Pawley profile fitting of the XRD pattern of $\chi$-alumina nanorods.

hkl Phase - 1 Pawley method

Phase name

R-Bragg

Space group

alumina

2.413

P6

Cell Volume $(\AA \wedge 3)$

240.16133 
PV_TCHZ peak type

$\begin{array}{ll}\mathrm{U} & 0.264463 \\ \mathrm{~V} & 0.1316646 \\ \mathrm{~W} & -0.189442 \\ \mathrm{Z} & 0 \\ \mathrm{X} & 0.07922793 \\ \mathrm{Y} & 0\end{array}$

Lattice parameters
a $(\AA)$
5.6744815
c $(\AA)$
8.6123182

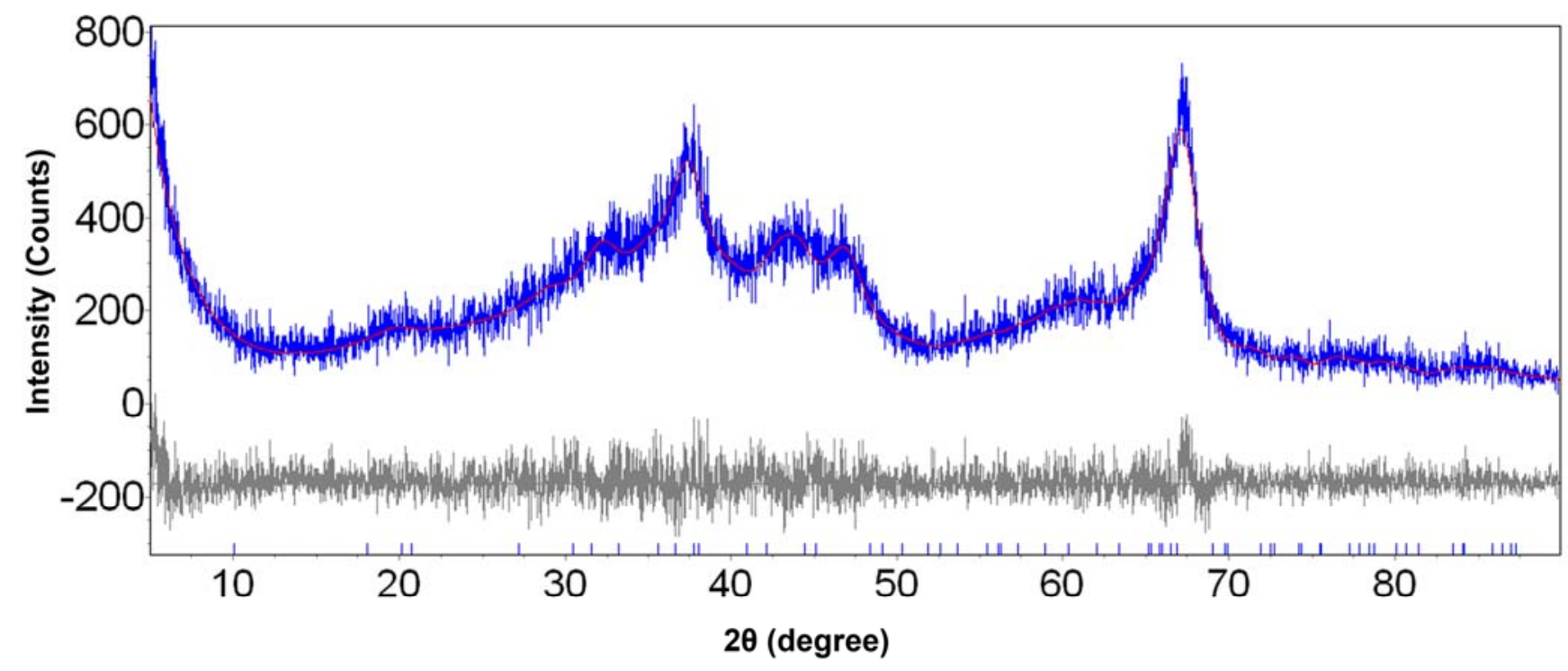

Fig. S1 XRD pattern of the nanorod specimen calcinated at 250 . Experimental and calculated XRD profiles and their difference.

III. The product synthesized in $\mathrm{H}_{2} \mathrm{O}$ 
$1.565 \mathrm{~g}$ CTAB was dissolved in $18 \mathrm{ml} \mathrm{H}_{2} \mathrm{O}$ to produce a CTAB solution. $1.207 \mathrm{~g}$ $\mathrm{AlCl}_{3} \cdot 6 \mathrm{H}_{2} \mathrm{O}$ and $0.80 \mathrm{~g} \mathrm{NaOH}$ were dissolved in $18 \mathrm{ml}$ deionized water to obtain a transparent $\mathrm{NaAlO}_{2}$ solution. The CTAB solution was added to the $\mathrm{NaAlO}_{2}$ solution under stirring. After $1 \mathrm{~h}$ stirring, the mixture was transferred into a Teflon-lined stainless autoclave and kept at $120^{\circ} \mathrm{C}$ for reaction for $10 \mathrm{~h}$. After cooling to room temperature, the final product was collected by centrifugation, washed with ethanol, and then vacuumdried at room temperature for $12 \mathrm{~h}$.

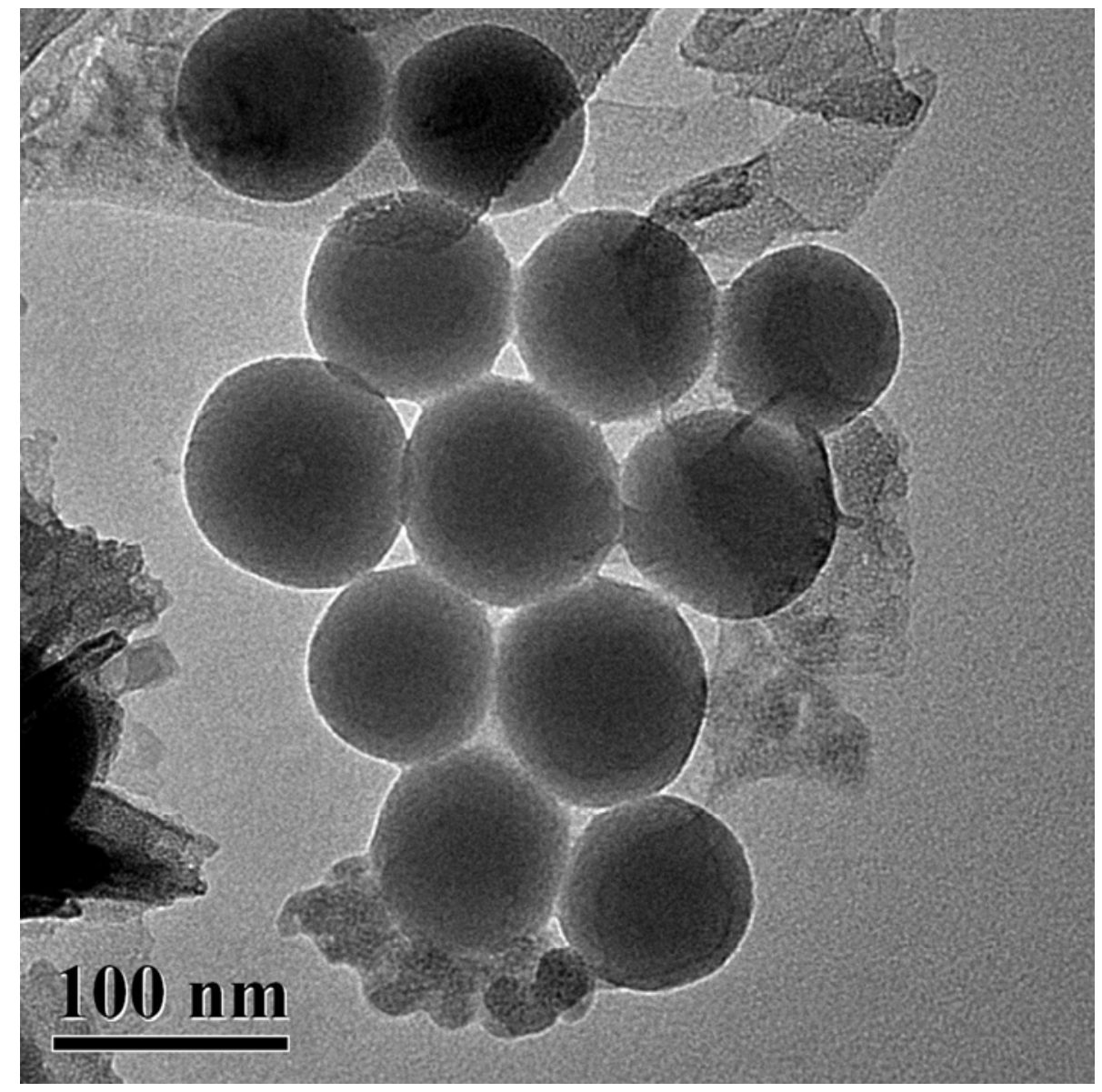

Fig. S2. TEM image of the product synthesized in $\mathrm{H}_{2} \mathrm{O}$ phase.

IV. The effect of the addition sequence of raw materials on the morphology of products: 
Method A:

$1.565 \mathrm{~g}$ CTAB was dissolved in $18 \mathrm{ml} \mathrm{EtOH}$ to produce a CTAB solution. $1.207 \mathrm{~g}$ $\mathrm{AlCl}_{3} \cdot 6 \mathrm{H}_{2} \mathrm{O}$ and $0.80 \mathrm{~g} \mathrm{NaOH}$ were dissolved in $18 \mathrm{ml}$ deionized water to obtain a transparent $\mathrm{NaAlO}_{2}$ solution. The CTAB solution was added to $\mathrm{NaAlO}_{2}$ solution under stirring. After $1 \mathrm{~h}$ stirring, the mixture was transferred into a Teflon-lined stainless autoclave and kept at $120^{\circ} \mathrm{C}$ for $10 \mathrm{~h}$. After cooling to room temperature, the final product was collected by centrifugation, washed with ethanol, and then vacuum-dried at room temperature for $12 \mathrm{~h}$. TEM pictures of the product are shown in Figure 2.

Method B:

$1.565 \mathrm{~g}$ CTAB and $0.80 \mathrm{~g} \mathrm{NaOH}$ were dissolved in $18 \mathrm{ml} \mathrm{EtOH}$ and $9.25 \mathrm{ml} \mathrm{H}_{2} \mathrm{O}$ to produce a transparent solution. $8.75 \mathrm{ml} 0.6 \mathrm{M} \mathrm{AlCl}_{3}$ solution was dropped into above mixture under drastic stirring. After $1 \mathrm{~h}$ stirring, the mixture was transferred into a Teflonlined stainless autoclave at $120^{\circ} \mathrm{C}$ for $10 \mathrm{~h}$. After cooling to room temperature, the final product was collected by centrifugation, washed with ethanol, and then vacuum-dried at room temperature for $12 \mathrm{~h}$. The corresponding TEM pictures are shown in Figure 6.

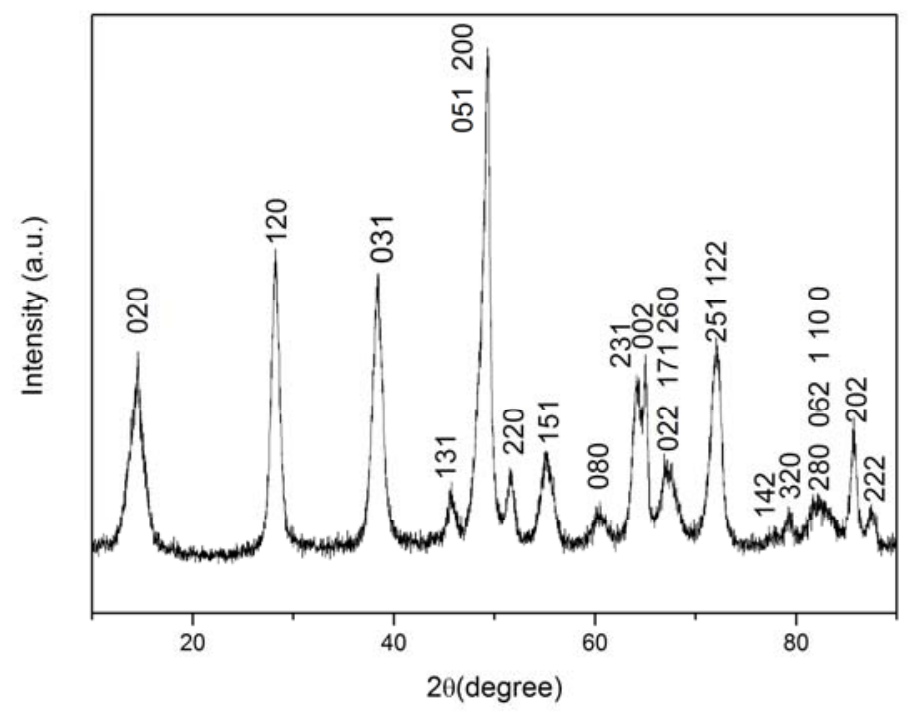

Fig.S3. XRD pattern of the products (nanotubes) obtained from method B. It is clear that boehmite nanostructures were obtained in this case. 